\title{
First monitoring and analysis of the manufacturing and installation process of timber based 2D modules for accomplishing a future robotic building envelope upgrading
}

\author{
K. Iturralde $1^{a}$, T. Linner $2^{\text {a }}$ T. Bock $3^{\text {a }}$ \\ ${ }^{a}$ Chair of Building Realization and Robotics, Technical University of Munich, Germany \\ E-mail: kepa.iturralde@br2.ar.tum.de, thomas.linner@br2.ar.tum.de, thomas.bock@br2.ar.tum.de
}

\begin{abstract}
-
The BERTIM Research Project is funded by the European Commission in order to develop a system for an efficient building envelope upgrading. The main goal of this envelope upgrading consists on adding a new 2D or 3D module onto the building external layer. The modules are made out of timber, thermal insulation and waterproof layers. These modules can also host some functionalities. In a previous phase, a method for implementing an efficient, integrated, modular and customized manufacturing and installation process of the BERTIM modules has been conceived. This method was achieved based on Axiomatic Design. The goal of this method was to generate and to coordinate three main sub-systems: the parametric design and configuration of the $2 \mathrm{D}$ and the $3 \mathrm{D}$ modules (1), the automated manufacturing process $(2)$ and the rapid robotic installation process (3). The Axiomatic Design was mainly used in order to detect the possible interferences of the disaggregated Functional Requirements regarding the Independence and Information Axiom and the main risks of a Coupled Design. The first demonstration of the manufacturing and installation process has taken part at the KUBIK experimental building. According to the Axiomatic Design Functional Requirements and the main Design Parameters defined in the previous phase, the demonstrator puts in evidence that the solutions taken don't fulfil the Independence and Information Axioms. The current system can be considered as a Coupled Design. In order to uncouple the system, the TRIZ inventive method has been used, focused on improving loss of time in all sub-systems. The solutions defined with TRIZ methods will be implemented in this three case studies carried out by three different industrial partners. The robotic and automated degree of each case will be adapted to the specifications of each demonstrator.
\end{abstract}

Keywords -refurbishing, customization, automated, prefabrication, Axiomatic Design, TRIZ

\section{Introduction}

A novel method of the manufacturing and installation process of prefabricated timber modules is being developed in the BERTIM [1] research project. As in every European Project, the research is based on Work Packages (WP) that are organized correlatively in a calendar. Within these WP there are tasks that focus on specific matters. The overarching technical objective of the BERTIM research project is to define a holistic building renovation process, based on digital data workflow. For that purpose, a general implementation methodology for the manufacturing and installing industry must be defined. Once this methodology is applied in the industry, there must be a reduction of $30 \%$ on the installation time of the modules, compared to traditional methods. As a previous excellent experience on the field, it must be mentioned the robotic installation of facades developed by Obayashi [1]. In this case, the façade prefabricated modules where rapidly and smoothly placed by an overhead robotic device. The modules are specifically designed for that robotic operation; the so called Robotic Oriented Design (ROD) Error! Reference source not found. concept was applied.
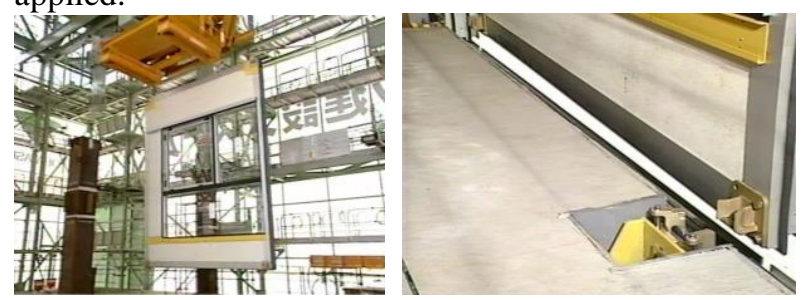

Figure 1. Ideal robotic façade installation by Obayashi. Right: Positioning of the façade element. Left: Compliant plug-and-play connector façade element. (images: Obayashi documentary video) [1].

The robotic installation process can be taken as a final 
goal, not only for the BERTIM project, but also for future building renovation projects. How to achieve that? It can be stated that the fast complying connectors, accurate manufacturing of the modules and specific robot devices are key factors. For that purpose, in the BERTIM project, a Set of Solutions has been defined in task 3.1 of WP3, that included:

- Generic design of the modules according to the requirements such as insulation, wind force and structural purposes. In this phase, a fast fitting connector has been conceived.

- The RenoBIM software will allow a repository of models and a fast integration onto the existing building's geometry.

- Definition of the manufacturing and installation processes and procedures that can be adapted to each manufacturer.

On these previous task 3.1, a generic and standard solution was defined. But when applying this solution to each specific building-case, some other steps must be considered.

- Measurement of the existing building-case. The main purpose of the measurement is to accurately adapt to the existing building.

- Re-design or adapt the BERTIM modules to the building-case using a CAD first and with RenoBIM afterwards.

- Manufacture the modules according to CAD or BIM.

- Prepare the building before installing the modules. With "preparing the building" it is meant the removal of unnecessary elements from the building.

- Install the modules. In principle, the ideal scenario would be to carry out a fast and smooth installation process while avoiding re-work.

In the Task 3.2 of Work-Package 3 of the BERTIM research project, a demonstrator was carried out at the "Kubik" building in Tecnalia's facilities in Bilbao, Basque Country (Spain). The Kubik building was built for carrying out tests, it is a test-building. The test consisted in installing five 2D modules onto the existing building façade. The re-designing, manufacturing and installation process where defined previously. The whole process, from first data acquisition to final installation, was monitored and the results, considering specially time, was analysed.

Once the installation was carried out, the members from Tecnalia monitored the thermal performance of the modules. Comparing to the previous Timber based research projects for building envelope renovation [4], the BERTIM modules can include services, generally hot water, ventilation ducts and also Renewable Energy Sources (RES). This adds extra complication to the design, manufacturing and installation processes, since the services must be accurately placed.

\section{Methodology}

The research methodology is based in two design procedures. The first is Axiomatic Design [5] and the second is TRIZ [6].Previous to this paper, in task 2.5 of Work-Package 2, the Axiomatic Design was drafted as a core for defining the strategy for implementation of the BERTIM project. In Task 5.1, this strategy must be implemented. But after the demonstrator in task 3.2, some of the concepts that were foressen need to be reviewed since the beforehand ideas haven't meet the expected results. The ongoing research is being carried out according to a methodology that is based in the next steps:

- Define the re-design, manufacturing and installation processes. This was already carried out in Task 3.2, previous to the demonstrator case.

- Implementation of the Kubik case study.

- Monitor the re-design, manufacturing and installation process of the Kubik case study.

- Get the results and analyze every break down form the monitoring process.

- Compare the results with the EIFS and rain-screen with the ones in Kubik BERTIM.

- Adapt the previously used Axiomatic Design process. Break every single task down based on the sub-systems of the Axiomatic Design proposed in previous research [8] focusing on the Design Process, Manufacturing process and Installation process.

- Allocate the points of the process that can be improved.

- Find possible applications according to the TRIZ contradiction matrix and the 40 Inventive Principles to these points.

- Discuss the Design Parameters or solutions for these points.

Once the discussion is finished, the next steps of the future research have been defined.

\section{Traditional methods: EIFS and rain- screen.}

The benchmark in BERTIM refers to the traditional methods for the installation process. In this research process two main types have been considered. The socalled EIFS (Exterior Insulation and Finish System) and the rain-screen. The data were gathered from a price and time database [7]. This row data of EIFS and rain-screen aren't comparable to the work that has been accomplished at Kubik during the BERTIM project demonstrator. They need to be combined and completed with some other tasks such as Service installation (12 linear meters of pipes) and perimeter finishing $(20,49$ 
linear meters of a metallic cover). Several parameters have been considered and estimated:

- $\quad \mathrm{Kh}$ : Total necessary working hours to achieve the works at Kubik

- NoW: Number of workers needed for each task.

- $\mathrm{Ku}$ : Area to be covered at the Kubik demonstrator.

- $\quad \mathrm{h} / \mathrm{m}^{2}$ : Total worker-hour task and square meter

These data have been gathered in Table 1 and Table 2 and will be used to compare the data from the BERTIM demonstrator process.

Table 1: Installation time for EIFS

\begin{tabular}{|c|c|c|c|c|}
\hline \multicolumn{5}{|c|}{ On-site ETICS at Kubik (simulation for comparison) } \\
\hline Task & $\mathrm{Kh}$ & NoW & $\mathrm{Ku}$ & $\mathrm{h} / \mathrm{m}^{2}$ \\
\hline Insulation & 5,09 & 2,00 & 23,34 & 0,22 \\
\hline Rendering & 30,63 & 2,00 & 23,34 & 1,31 \\
\hline Painting & 7,10 & 2,00 & 23,34 & 0,30 \\
\hline Perimeter & 20,20 & 2,00 & 20,49 & 0,99 \\
\hline Services & 2,58 & 2,00 & 12,00 & 0,22 \\
\hline \multicolumn{5}{|c|}{ TOTAL $\mathbf{h} / \mathbf{m}^{2}$ WITH SERVICES } \\
\hline \multicolumn{4}{|c|}{ TOTAL $\mathbf{h} / \mathrm{m}^{2}$ WITHOUT SERVICES } & 2,82 \\
\hline
\end{tabular}

Table 2: Installation time for rain-screen

\begin{tabular}{lllll}
\hline \multicolumn{5}{c}{ On-site rain-Screen at Kubik (simulation for comparison) } \\
\hline \multicolumn{1}{c}{ Task } & $\mathrm{Kh}$ & $\mathrm{NoW}$ & $\mathrm{Ku}$ & $\mathrm{h} / \mathrm{m}^{\mathbf{2}}$ \\
\hline Insulation & 6,44 & 2,00 & 23,34 & 0,28 \\
rain-screen & 43,09 & 2,00 & 23,34 & 1,85 \\
Perimeter & 20,20 & 2,00 & 20,49 & 0,99 \\
Services & 2,58 & 2,00 & 12,00 & 0,22 \\
\hline
\end{tabular}

\begin{tabular}{rrr} 
TOTAL $\mathbf{h} / \mathbf{m}^{2}$ WITH SERVICES & $\mathbf{3 , 3 2}$ \\
\hline TOTAL $\mathbf{h} / \mathbf{m}^{2}$ WITHOUT SERVICES & $\mathbf{3 , 1 1}$ \\
\hline
\end{tabular}

As an objective of the BERTIM project, the time collected in this table need to be reduced by $30 \%$. We can therefore set as a benchmark 2 worker-hours $/ \mathrm{m}^{2}$ for the modules with services and 1,75 worker-hours $/ \mathrm{m}^{2}$ for the modules without services.

\section{Definition of "standard " BERTIM modules}

The criteria for the detailed design of the BERTIM modules have been defined in task 3.1 of WP 3 according to the Requirements specified in task 2.3 of WP 2. For the façade 2D modules the next points were specified:

- Criteria for the Energy Efficiency of the Modules: it included insulation type, thermal performance, condensation, HVAC and energy consumption.

- Criteria for the Design of the 2D Envelope Modules with and without Services: it included structural design, three different support systems, fire resistance and quick fit of services.

After defining how the "standard" BERTIM modules must be manufactured, transported and installed, a demonstrator was carried out at the Kubik building.

\section{Implementing the BERTIM 2D modules to the Kubik case study}

The solutions taken for carrying out this demonstrator included new features, but it didn't differ relevantly with the traditional techniques that are used by one of the industrial partners within the BERTIM consortium. It has to be said that this demonstration was carried out as a relevant environment test and some results were marked and analyzed. The Kubik building is a test building. It has to be said that the demonstrator at the Kubik building it is not a standardized procedure, and therefore it is more prompt to errors than traditional and already tested, proofed and commercialized techniques and procedures.

The modules used in the Kubik demonstrator were manufactured by the industrial partner Egoin. As said before, there were five $2 \mathrm{D}$ modules installed onto the building's façade. Three of them didn't have any services. The rest two included services, such as hot water and ventilation ducts. The purpose of placing services in the Kubik module was purely for testing the easiness of the installation process and monitoring the heat loss through the service module itself.

\subsection{Monitoring the manufacturing and installation process}

If we consider the whole process, from the very beginning of preliminary work to the last detailing and finalization, the procedure for manufacturing and installing the BERTIM prefabricated 2D modules took in total two months. But there were some idle periods as it can be seen on the following chronological timeline:

\section{On-site at Kubik building}

- 2016-10-03 Dismantle previous façade element. This façade was from a previous project. This step is not considered in the total sum of time.

- 2016-10-18 Measure the existing building with total station as seen in Figure 2. The criteria for measuring, in this case where there are no windows, is based on localizing the perimeter strategic points.

- 2016-10-19 Making holes for connecting services in the interior. As said before, the modules will be equipped with services that need to be fit with the 
internal heating system.
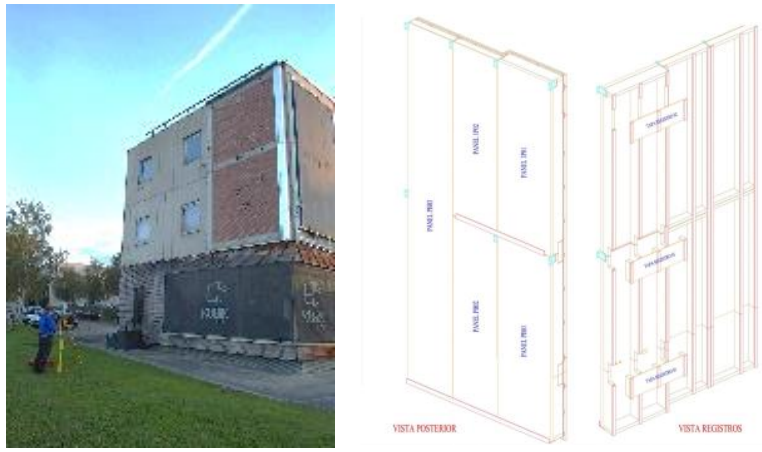

Figure 2. Left: Measuring the Kubik building strategic points. Right: Define the modules in CAD.

\section{Off-site, in Egoin factory facilities}

- 2016-11-14 Define the modules in CAD according to the measurements (Figure 2 right).

- 2016-11-15 Manufacture the modules according to the CAD files. The main process consisted on cutting studs, mill the studs, conform the frame and place the board (Figure 3 left). Next, they placed the vapor barrier and insert insulation. If the module had services, these were inserted at this point (Figure 3 middle). Finally, the moisture barrier and the raster were assembled. The finishing grid was manufactured separately (Figure 3 right). After the modules were assembled, they were mounted onto a truck for transportation.
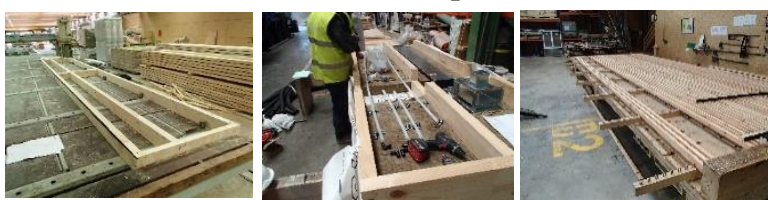

Figure 3: Manufacturing process of the modules.

Left: Timber-frame manufacturing. Middle: assembly of services onto the module. Right:

Manufacture of finishing grid.

\section{On-site at Kubik building}

- 2016-11-22 and 23: Download the modules from the truck. After that, the first structural profile was placed Next, the insulating layer was fixed. Once the wall was prepared, finally the $2 \mathrm{D}$ modules bodies were placed and fixed (Figure 4).
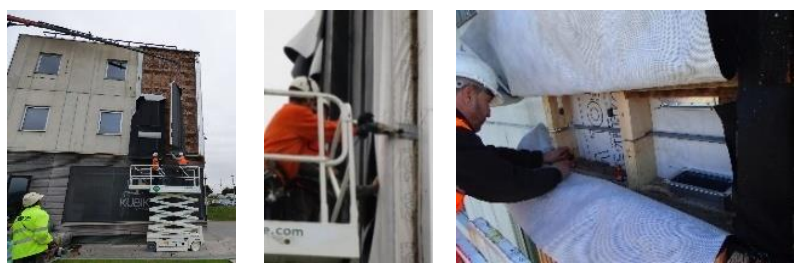

Figure 4. Left: Installing the panels. Middle: Fixing the connector to the wall. Right: Joining and fitting services.

- 2016-11-24 and 25. During these days the services were fitted, which means to fit the services within the modules and to fit the services on the interior of the building.

- 2016-11-28 Perimeter cladding and some other finishing was carried out.
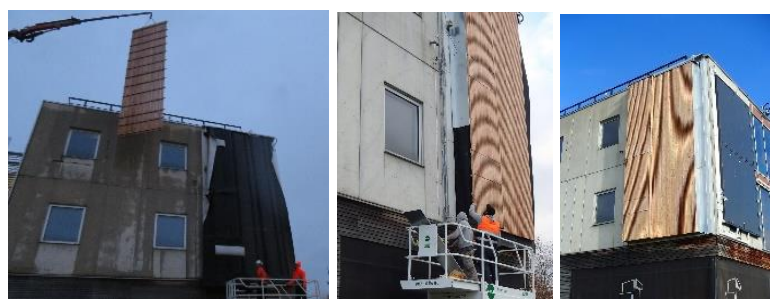

Figure 5. Left and middle: Placement and fixation of the finishing timber grid. Right: Final enclosure and perimeter finishing.

Table 3: Manufacturing and installation time required for the 2D BERTIM modules at the Kubik bulding.

\begin{tabular}{ccccc}
\hline Task & $\mathrm{Kh}$ & $\mathrm{NoW}$ & $\mathrm{Ku}$ & $\mathrm{Kh} / \mathrm{m}^{\mathbf{2}}$ \\
\hline \multicolumn{5}{c}{ RE-ENGINEERING } \\
\hline Data acquisition & 2,00 & 1,00 & 23,34 & 0,09 \\
Re-design & 8,00 & 1,00 & 23,34 & 0,34 \\
\hline
\end{tabular}

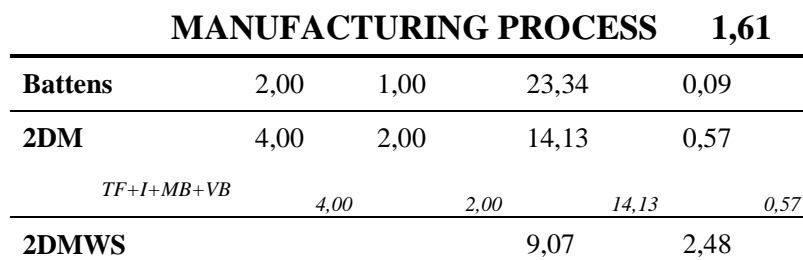

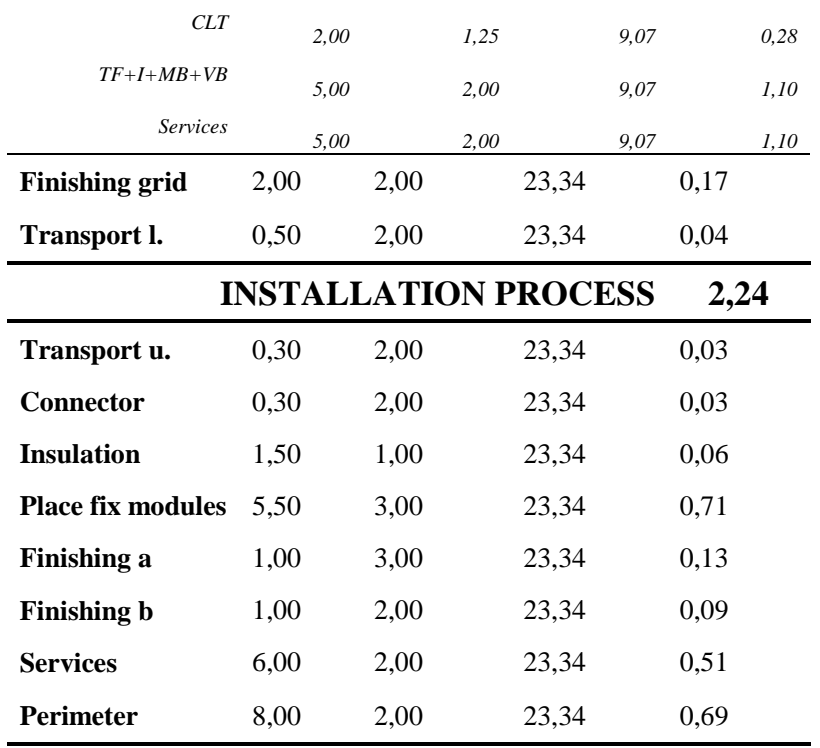

TOTAL $\mathrm{h} / \mathrm{m}^{2}$ WITH SERVICES 4,27 TOTAL $\mathrm{h} / \mathrm{m}^{2}$ WITHOUT SERVICES 3,21 
As said before, the whole process was monitored. Basically, it was focused on how many workers and how much time were used in each part of the task. Following the criteria of Table 1, the same parameters were recorded during the whole process. In the case of BERTIM, though, the off-site manufacturing process was also recorded and monitored as it can be seen in Error! Reference source not found.

As it can be seen in Table 3, the whole process is divided in three different stages. First there is the reengineering process which consist on the data acquisition of the existing building and the adaptation of the BERTIM module to the building's needs. After that, there is the manufacturing process. In this phase, the battens are cut and machined first. Two types of modules can be divided: modules without services (2DM) and modules with services which are reinforced with CLT panels (2DMWS). In both cases they consist of assembling timber frame (TF), insulation (I), moisture barrier (MB) and vapor barrier (VB). Once the modules are produced and transported to the site, the installation process starts.

\subsection{Discussion about results}

In previous data gathering, the authors detected that 1,18 hour $/ \mathrm{m}^{2}$ were necessary for the manufacturing process [8]; this shows the data are quite similar to the $1,30 \mathrm{~h} / \mathrm{m} 2$ registered for the Kubik case. The manufacturing process differs from one industrial partner to the other, depending on the facilities and assets they have for producing the modules. One of the analysed partners showed that the $0,8 \mathrm{~h} / \mathrm{m}^{2}$ would be reached if dedicated work station are organized properly. Therefore, it can be said that there is already technology for automating and improving the manufacturing process.

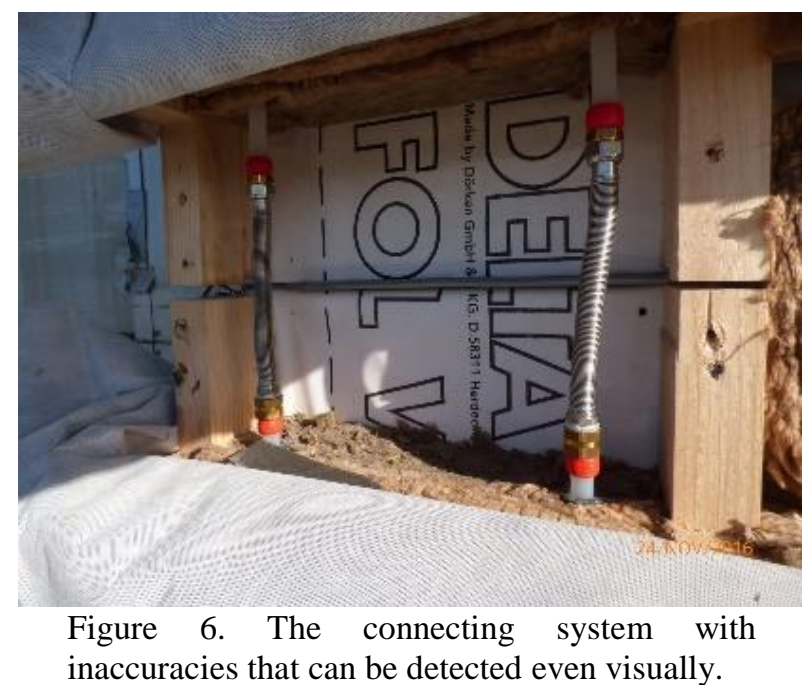

Regarding $o$ the finishing of the modules, an inaccuracy of around $10 \mathrm{~mm}$ has been found in the final positioning of the modules. The errors might be produced by:

- Inaccuracy of the manufacturing process.

- Inaccuracy of the positioning of the support.

- Inaccuracy during the placement of the modules .

- Un-rigidness of the timber modules, which during transportation can be bended and deformed. Also, the modules can expand or shrink due to hydrothermal changes.

Due to this inaccuracy, the tubes are not ready to fit and they need a rework (more time for fitting) at the construction site.

\subsubsection{Re-engineering process. Design adaptation}

The re-engineering process for nesting and drawing the modules takes $0,34 \mathrm{~h} / \mathrm{m}^{2}$. Without the RenoBIM software tool this is a time consuming task that in the case of the Kubik case study, it took around 8 hours to redesign the modules. Besides the RenoBIM, the use of some other parametric design software would be necessary in order to automate the process.

\subsubsection{Place and fix the modules and the finishing grid.}

The installation of the modules takes $0,71 \mathrm{~h} / \mathrm{m} 2$. This time includes the module itself and but not the finishing grid, which is placed afterwards. Installing the finishing takes $0,22 \mathrm{~h} / \mathrm{m} 2$. If the module was a fully prefabricated with integrated finishing, time reduction would be enhanced. The same happens with the insulating layer that is placed on the wall before the installation of the modules.

\subsubsection{Fitting of services on-site}

The fitting of the services consisted on joining together the water and air ducts in a registrable box. This was a manual operation. Furthermore, the whole box needed to be insulated and covered after that. The joining tubes where flexible in order to have bigger tolerances in case of big accuracy errors. Definitely, this can be considered as a time consuming task, and therefore a solution should be considered.

\subsubsection{Finishing perimeters}

This task requires major study definitely, since 0,69 $\mathrm{h} / \mathrm{m} 2$ were necessary for that purpose. It could be considered even a bigger problem if there were windows involved. In the Kubik demonstrator there was no window within the modules. As a previous experience for adapting to the windows particular geometry, a set of solutions was already proposed in the RetroKit project [9]. But in this case, the level of prefabrication was lower than in BERTIM. In future BERTIM tests and 
demonstrators, the issue of fitting the 2D module to the window must be solved.

\subsection{The Axiomatic Design matrix of the Kubik demonstrator}

As a conclusion of the Kubik demonstrator, it was clear that the manufacturing and installation process and the module itself still needs to be re-adapted in order to improve the time schedule of the whole process. The H2020 EE-01-2014 call named "Manufacturing of prefabricated modules for (energy) renovation of buildings", defined the next main requirements:

- Use prefabricated modules. It must be said that there is an underneath objective to integrate energy efficiency devices and renewable energy sources in the prefabricated multi-functional modules.

- Use of advanced computer based tools for integrating the value chain over the life cycle of the project.

- Move from individual manufacturing to mass production. A more accurate term would be masscustomization.

- Reduce the installation time by at least $30 \%$, compared to a typical renovation process for the building type. This term must be defined more accurately. In this research, we compute or determine the total time of Re-design, Manufacturing and Installation processes. And that time should be lower than the traditional methods.

Other minor objectives that can be considered also as constrains are:

- Reduce costs. This is related to the manufacturing and installation processes.

- Ensure quality

- Facilitate dismantling and re-use

- Improve on-site health and safety during manufacturing and installation.

In the BERTIM project, in previous approaches [8], the Functional Requirements (FR) for accomplishing these previous objectives were defined. In this previous phase, specific solution weren't given, at least in the lowest hierarchy of the sub-systems; particular and disaggregated requirements weren't solved. The idea is that the timber-frame manufacturers can apply this method with enough flexibility, depending on the current economic and technical limitations. Comparing to previous approaches, a new sub-system has been added, sub-system 2 as it can be seen on the next list:

- Sub-system 1: Customize the prefabricated 2D modules for specific building refurbishment.

- Sub-system 2: Information workflow based on advanced software.
- Sub-system 3: Maximize the offsite manufacturing process of existing facilities of the industrial manufacturers.

- Sub-system 4: Minimize onsite Installation time and cost of the module

On the other hand, the Design Parameters where considered the next:

- Sub-system 1: Use of highly prefabricated and adaptable timber-framed modules

- Sub-system 2: Use of RenoBIM for the integrated Product Lifecycle Management (PLM).

- Sub-system 3: Use of a Manufacturing Modular Kit that can be adapted to the manufacturers

- Sub-system 4: Define a Rapid Installation System

But on the Kubik demonstrator, these sub-systems were not fully implemented, and the primary hierarchy of the Axiomatic Design was modified as follows:

$F R=A * D P$

$$
\left\{\begin{array}{l}
F R_{1} \\
F R_{2} \\
F R_{3} \\
F R_{4}
\end{array}\right\}=\left\{\begin{array}{cccc}
x & A_{12} & A_{13} & A_{14} \\
A_{21} & x & A_{23} & A_{24} \\
A_{31} & A_{32} & x & A_{34} \\
A_{41} & A_{42} & A_{43} & x
\end{array}\right\} *\left\{\begin{array}{l}
D P_{1} \\
D P_{2} \\
D P_{3} \\
D P_{4}
\end{array}\right\}
$$

(A) $\quad \boldsymbol{F R}_{\mathbf{1}}=$ Definition $2 D$ prefabricated modules for building refurbishment

(B) $\quad \boldsymbol{F} \boldsymbol{R}_{2}=$ Information workflow based on digital Data CAD - CAM systems

(C) $\quad \boldsymbol{F R}_{3}=$ Maximize the off - site manu facturing process

(D) $\quad F_{\boldsymbol{R}_{4}}=$ Minimize onsite Installation time and cost

(A) $\quad \boldsymbol{D} \boldsymbol{P}_{\mathbf{1}}=$ Adaptable, medium - prefabricated modules with limited acuracy

(B) $\quad \boldsymbol{D} \boldsymbol{P}_{2}=$ Use of conventional CAD systems for the definition of the modules

(C) $\boldsymbol{D} \boldsymbol{P}_{3}=$ Exisitng factories with limited flexibility and no dedicated workstations

(D) $\quad \boldsymbol{D} \boldsymbol{P}_{4}=$ Conventional fixation process with a mobile crane and a platform

Table 4: Interference Matrix

\begin{tabular}{|l|l|l|l|l|}
\hline & DP1 & DP2 & DP3 & DP4 \\
\hline FR1 & $x$ & $x$ & 0 & 0 \\
\hline FR2 & $x$ & $x$ & $x$ & 0 \\
\hline FR3 & $x$ & $x$ & $x$ & 0 \\
\hline FR4 & 0 & $x$ & 0 & $x$ \\
\hline
\end{tabular}

If we check this primary hierarchy in a matrix table, we can see that the Independence Axiom is not fulfilled fully. There are interferences between the different FRs and DPs is considerable as it is shown in Table 4.For instance these are the points that need to be taken into consideration:

- Sub-system 1: In the case of the Kubik building, the adaptable prefabricated modules had a medium degree of prefabrication. Only around $50 \%$ of the tasks were carried out at the factory. The adaptable module needed special rework after being placed and fixed on to the wall; the finishing was necessary and the services need to be fit.

- Sub-system 2: The customization of the module affected the CAD re-design process. The manual adaptation of the CAD file, slows down the process. Furthermore, in the manufacturing process, the works 
need to be guided by the engineer in charge.

- Sub-system 3: Using the existing tools and assets offsite on the factory, the continuous customized modules and its bespoken process can diminish the productivity.

- Sub-system 4: The installation can't be minimized if the prefabricated product, after installation, needs rework such as the perimeter enclosure finishing or the window frame finishing. Besides, the service fitting time should be diminished too. It can be said that the highly prefabricated modules needs to meet the geometry of the existing wall accurately.

Therefore, the strategies need to be re-defined. On the next chapter, some broken down parts of the process will be analysed and the TRIZ method will be applied.

\section{Implement TRIZ}

The TRIZ method facilitates the identification of the so called contradictions that a system might have. These contradictions block or obstruct the possibility of improvement of a system. But thanks to the TRIZ Parameter Matrix and the 40 Inventive Principles, the problems are detected and diverted to find an optimal solution. In order to reduce time, the manufacturing, but specially the installation process needs to be fast. If we take as a primary objective to reduce time, we can organize the TRIZ strategy as follows.

\subsection{Time reduction in the installation process}

The time reduction in installation will come from a higher prefabrication and accuracy of the modules in order to obtain a fast fitting process and avoid re-work.

But a fast installation process and a high accuracy leads to lack on the ease of operation. The connectors on the wall need to be aligned with low tolerances in order the module and services fit. The TRIZ matrix provides the principles 4,28,10 and 34 for this situation (

Table 5). The principle 10, preparation of the alignment of the wall has been used already in some other similar research projects [10][11], but that leads again back to a loss of time.

Besides, the module might change its configuration during transportation due to heat and humidity changes, and therefore, the accuracy can be lost during logistics operations. This issue must be taken into consideration on next phases.

Table 5: Principles 4 (asymmetry), 28 (replace mechanics), 10 (prior action and pre-arrange objects) and 34(discard and remove)

\begin{tabular}{|l|l|}
\hline & Ease of operation(32) \\
\hline Loss of time (25) & $4,28,10,34$ \\
\hline
\end{tabular}

\subsection{An accurate module for rapid processes}

The defined module needs to be highly prefabricated, and therefore, highly defined in order to loose time. In consequence, a highly prefabricated module which includes embedded services needs high accuracy in order to be fit rapidly. For a higher accuracy of the modules, there must be an accurate data acquisition of the existing building in order to customize and bespoke the modules. However, the biggest contradiction of the highly prefabrication relies on the lack of adaptability of the module, that the module is so tight that no change is possible. TRIZ offers two principles for these situation, 35 (parameter change) and 28 (replace mechanics) as it can be seen in Table 6 . This is related to the module materials and configuration. The materials and elements of the module need to be reviewed. Besides, a highly defined parametric design of the BERTIM module properly linked with the CAM would facilitate the procedure.

Table 6: Principles 35(parameter change) and 28 (replace mechanics)

\begin{tabular}{|l|l|}
\hline & Adaptability (35) \\
\hline Loss of time (25) & 35,28 \\
\hline
\end{tabular}

\subsection{Time reduction in the re-design and digital workflow}

Once the re-design process is ready, ease of manufacturing must be accomplished, with a clear digital information and material workflow. And it takes time during the manufacturing process and installation process if the elements, specially the services are not clearly described for the operator. The biggest harm is therefore the loss of information, the operator doesn't know how to assembly every customized module. Besides, as said before, the customization of the module takes time on the manufacturing process, especially if no parametric or computational design feature is used and the elements are drawn in CAD manually. In this situation TRIZ offers principles 24, 26, 28 and 32 (Table 7). Among them, the " copying" principle is the most adequate for our case, basically, what needed is a clear parametric library of solutions that will " copy" the module's configuration successively on the next cases.

Table 7: 24(intermediary), 26 (copying), 28 (replace mechanical system), 32 (change color)

\begin{tabular}{|l|l|}
\hline & Loss of information (35) \\
\hline Loss of time (25) & $24,26,28,32$ \\
\hline
\end{tabular}

\subsection{Accuracy in the manufacturing process}

Gaining accuracy leads to a loss productivity in 
manufacturing processes. Among the principles proposed by TRIZ, the "discard and remove" might be the most interesting. This principle would lead to use of patterns that can facilitated the insertion of services onto the modules.

Table 8: 35 (parameter change), 28(replace mechanics), 34 (discard and remove), 4 (asymmetry)

\begin{tabular}{|l|l|}
\hline & Productivity (32) \\
\hline Manufacturing accuracy (25) & $35,28.34,4$ \\
\hline
\end{tabular}

\subsection{New Axiomatic Design matrix and discussion}

In theory, if the Inventive Principles are implemented the Axiomatic Design matrix should be uncoupled as it can be seen on the next matrix and on Error! Reference source not found.. It has been prioritized the reduction of time during the installation process and the rest of requirements are hierarchited for that purpose. Though, the given solutions aren't still detailed enough to prove that the matrix would be uncoupled yet. But it gives a direction for the next research steps in order to fulfill the Independence Axiom.

$F R=A * D P$

$\left\{\begin{array}{l}F R_{1} \\ F R_{2} \\ F R_{3} \\ F R_{4}\end{array}\right\}=\left\{\begin{array}{cccc}x & A_{12} & A_{13} & A_{14} \\ A_{21} & x & A_{23} & A_{24} \\ A_{31} & A_{32} & x & A_{34} \\ A_{41} & A_{42} & A_{43} & x\end{array}\right\} *\left\{\begin{array}{l}D P_{1} \\ D P_{2} \\ D P_{3} \\ D P_{4}\end{array}\right\}$

(A) $\quad \boldsymbol{F} \boldsymbol{R}_{\mathbf{1}}=$ Definition $2 D$ prefabricated modules for building refurbishment

(B) $\quad \boldsymbol{F} \boldsymbol{R}_{2}=$ Information workflow based on digital Data CAD - CAM systems

(C) $\quad \boldsymbol{F} \boldsymbol{R}_{3}=$ Maximize the of $f$ site manufacturing process

(D) $\quad \boldsymbol{F}_{\mathbf{4}}=$ Minimize onsite Installation time and cost

(A) $\boldsymbol{D} \boldsymbol{P}_{\mathbf{1}}=$ Accurate andfully prefabricated module

(B) $\quad \boldsymbol{D} \boldsymbol{P}_{2}=$ Parametric definition of the modules using computational design

(C) $\quad \boldsymbol{D} \boldsymbol{P}_{3}=$ Dedicated workstations for services integrated on existing factories

(D) $\quad \boldsymbol{D P}_{\mathbf{4}}=$ Rapid placement and fixation process using interfaces

Table 9: interference matrix

\begin{tabular}{|l|l|l|l|l|}
\hline & DP1 & DP2 & DP3 & DP4 \\
\hline FR1 & $x$ & 0 & 0 & 0 \\
\hline FR2 & 0 & $x$ & 0 & 0 \\
\hline FR3 & 0 & 0 & $x$ & 0 \\
\hline FR4 & 0 & 0 & 0 & $x$ \\
\hline
\end{tabular}

\section{Conclusions}

TRIZ has been useful for uncoupling the Axiomatic Design Matrix in the case of BERTIM. But a broader study is necessary to reach specific solutions. The specific and detailed solutions are being defined currently. It can be said that TRIZ is being a suitable method for gathering different conceptual and specific solutions. Two criteria can be outlined from this research.
First, the higher the prefabrication, the lower time for onsite installation and rework. Second, the higher prefabrication, the more accuracy is needed, and therefore more time is necessary in measuring and manufacturing. On future works, other Functional Requirements should be analyzed and researched. The authors will follow working on that direction. Currently they are studying fitting the Axiomatic Design objectives with the 39 Parameters on the Contradiction Table of TRIZ. The discussion is if one or more parameters need to be used in the finding of a solution.

The main outcome of this research, especially regarding the accuracy of the modules and the fast fixation system, should be considered for future strategies of robotized and automated manufacturing and installation processes in building renovation and maintenance. Before the end of the BERTIM research project, the modules will be manufactured and installed in three different operational environments, in real building refurbishment projects. The research presented on this paper will be applied to these cases.

\section{Acknowledgments}

This paper has been drafted thanks to the funding from the European Union's Horizon 2020 research and innovation programme under grant agreement No 636984. The content of this paper does not reflect the opinion of the European Union.

\section{References}

[1] Bock, T., Linner, T., 2016, Site Automation, Cambridge University Press.

[2] Bock, T. and Linner, T., 2015. Robot Oriented Design. Cambridge University Press.

[3] Webpage visited the 15/03/2016: http://bertim.eu

[4] Larsen, K. E., et al., "Surveying and digital workflow in energy performance retrofit projects using prefabricated elements", Automation in construction, 2011.

[5] Suh, Nam P. "Axiomatic Design: Advances and Applications (The Oxford Series on Advanced Manufacturing)." (2001).

[6] Ogot, M. "Conceptual design using axiomatic design in a TRIZ framework." Procedia Engineering 9 (2011): 736-744.

[7] Webpage visited the 15/03/2016: http://www.generadordeprecios.info/

[8] Iturralde, K., Linner, T., Bock, T., Development of a modular and integrated product-manufacturinginstallation system kit for the automation of the refurbishment process in the research project BERTIM 2016 Proceedings of the 33rd ISARC, Auburn, USA

[9] Webpage visited the 15/03/2016: http://www.retrokitproject.eu/

[10] Larsen, K. E., et al., "Surveying and digital workflow in energy performance retrofit projects using prefabricated elements", Automation in construction, 2011.

[11] VariousAuthors, “Großelement-Dämmtechnik mit 
$34^{\text {th }}$ International Symposium on Automation and Robotics in Construction (ISARC 2017)

Vakuumdämmung", Institut Wohnen und Umwelt GmbH, Endbericht, Germany, 2007 